\title{
Analysis of the Fuel Economy Benefit of Drivetrain Hybridization
}

Matthew R. Cuddy

Keith B. Wipke

Prepared for

SAE International Congress \& Exposition February 24-27, 1997

Detroit, Michigan

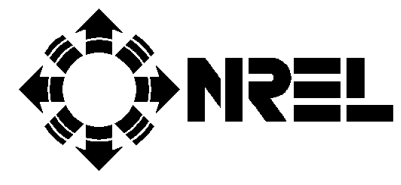

National Renewable Energy Laboratory 1617 Cole Boulevard Golden, Colorado 80401-3393

A national laboratory of the U.S. Department of Energy Managed by Midwest Research Institute for the U.S. Department of Energy under contract No. DE-AC36-83CH10093

Work performed under Task No. HV716010

January 1997 


\begin{abstract}
NOTICE
This report was prepared as an account of work sponsored by an agency of the United States government. Neither the United States government nor any agency thereof, nor any of their employees, makes any warranty, express or implied, or assumes any legal liability or responsibility for the accuracy, completeness, or usefulness of any information, apparatus, product, or process disclosed, or represents that its use would not infringe privately owned rights. Reference herein to any specific commercial product, process, or service by trade name, trademark, manufacturer, or otherwise does not necessarily constitute or imply its endorsement, recommendation, or favoring by the United States government or any agency thereof. The views and opinions of authors expressed herein do not necessarily state or reflect those of the United States government or any agency thereof.
\end{abstract}

Available to DOE and DOE contractors from:

Office of Scientific and Technical Information (OSTI)

P.O. Box 62

Oak Ridge, TN 37831

Prices available by calling 423-576-8401

Available to the public from:

National Technical Information Service (NTIS)

U.S. Department of Commerce

5285 Port Royal Road

Springfield, VA 22161

703-605-6000 or 800-553-6847

or

DOE Information Bridge

http://www.doe.gov/bridge/home.html 


\title{
Analysis of the Fuel Economy Benefit of Drivetrain Hybridization
}

\author{
Matthew R. Cuddy and Keith B. Wipke \\ National Renewable Energy Laboratory
}

\begin{abstract}
Parallel- and series-configured hybrid vehicles likely feasible in next decade are defined and evaluated using

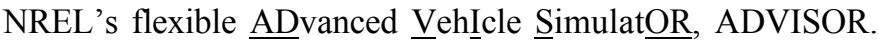
Fuel economies of these two diesel-powered hybrid vehicles are compared to a comparable-technology diesel-powered internal-combustion-engine vehicle. Sensitivities of these fuel economies to various vehicle and component parameters are determined and differences among them are explained. The fuel economy of the parallel hybrid defined here is $24 \%$ better than the internal-combustion-engine vehicle and $4 \%$ better than the series hybrid.
\end{abstract}

\section{INTRODUCTION}

Automobile drivetrain hybridization (using two types of energy converters rather than just one, as conventionaldrivetrain vehicles do) is considered an important step to high fuel economy. The Department of Energy has established cost-shared programs with Chrysler, Ford, and General Motors under the Hybrid Vehicle Propulsion System Program to double the fuel economy of midsized automobiles, without sacrificing performance and consumer acceptability, by hybridizing their drivetrains. The government/industry Partnership for the New Generation of Vehicles (PNGV) effort has also identified hybridization as an important step toward tripling mid-sized sedan fuel economy. Recent and ongoing work seeks both to identify the likely fuel economy gains hybrid vehicles can deliver, and to ascertain the hybrid configuration that will lead to the best fuel economy [1-6].

Tamor, of Ford Motor Co., uses energy throughput spectra of current internal-combustion-engine vehicles (ICEVs) along with Ford Ecostar electric-drive data and an idealized battery model to estimate the greatest possible benefit of drivetrain hybridization to be $50 \%$ [6]. Given a $100 \%$ efficient energy storage system and ideal control stragegy, Tamor estimates a parallel hybrid will have a combined federal fuel economy of roughly 1.5 times the fuel economy of an ICEV of similar mass and engine technology. (Combined federal fuel economy is computed assuming 55\% of miles are driven on the USEPA Federal Urban Drive Schedule (FUDS) and $45 \%$ on the USEPA Federal Highway Drive Schedule (FHDS).) Further, Tamor concludes that engine and road loads being equal, a parallel hybrid is more fuel-efficient than a series hybrid. Mason and Kristiansson, however, assert that series hybrids are likely to be more fuelefficient than parallel hybrids [7]. Initial studies at NREL using current and projected component data indicated that series and parallel hybrids have similar fuel economy potential [8].

This analysis predicts the fuel economy differences among a series hybrid, a parallel hybrid, and an ICEV of similar levels of advancement and performance, using component and vehicle data adapted from current technologies. The methods of analysis and assumptions required are presented. The dependence of the fuel economy of each vehicle upon the assumptions are presented, allowing an understanding of the various projections of hybrid fuel economy made in the literature. Sensitivity coefficients, required for the fuel economy sensitivity analysis and analogous to the "influence coefficients" discussed by Sovran and Bohn are also presented [9]. These sensitivity coefficients may be used to estimate the fuel economy of derivatives of the vehicles presented.

The National Renewable Energy Laboratory's

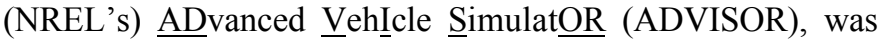
used along with data from the literature and from industry contacts to define and evaluate charge-sustaining hybrids (which may operate without wall-charging, as long as there is fuel in their tank) and a ICEV for comparison. ADVISOR was also used to determine numerically the sensitivity of each vehicle's fuel economy to changes in vehicle and component parameters. These sensitivities were then used to analyze the predicted fuel economy differences among the three vehicles.

The only vehicle figure of merit being considered here is fuel economy. We recognize that there are many other important issues to be resolved in the development of a vehicle such as cost, reliability, and emissions. Our focus here, however, is solely on the likely potential to improve fuel 
economy by drivetrain hybridization. With that focus, we found the series hybrid defined here is $18 \%$ more fuelefficient than the ICEV and the parallel hybrid is $24 \%$ more fuel-efficient than the ICEV. A $10 \%$ drop in battery turnaround efficiency (from $\sim 88 \%$ to $\sim 80 \%$ ) causes a $1.5 \%$ drop in series hybrid fuel economy (for this particular control strategy) and a $1.3 \%$ drop in parallel hybrid fuel economy. The sensitivity to regenerative braking effectiveness is likewise small: a $10 \%$ drop in regenerative braking effectiveness causes a $0.7 \%$ drop in parallel hybrid fuel economy and a $1.0 \%$ drop in series hybrid fuel economy.

\section{BASELINE VEHICLES}

The vehicles used in this study were defined using current and projected vehicle and component data. Using NREL's vehicle performance simulator, ADVISOR, (which has been benchmarked against industry simulation tools,) the components were sized to meet performance goals, and transmission and hybrid control strategies were optimized for fuel economy subject to performance constraints. ADVISOR was then used to evaluate the vehicles' fuel economy. The vehicles in this study are shown schematically in Figure 1.

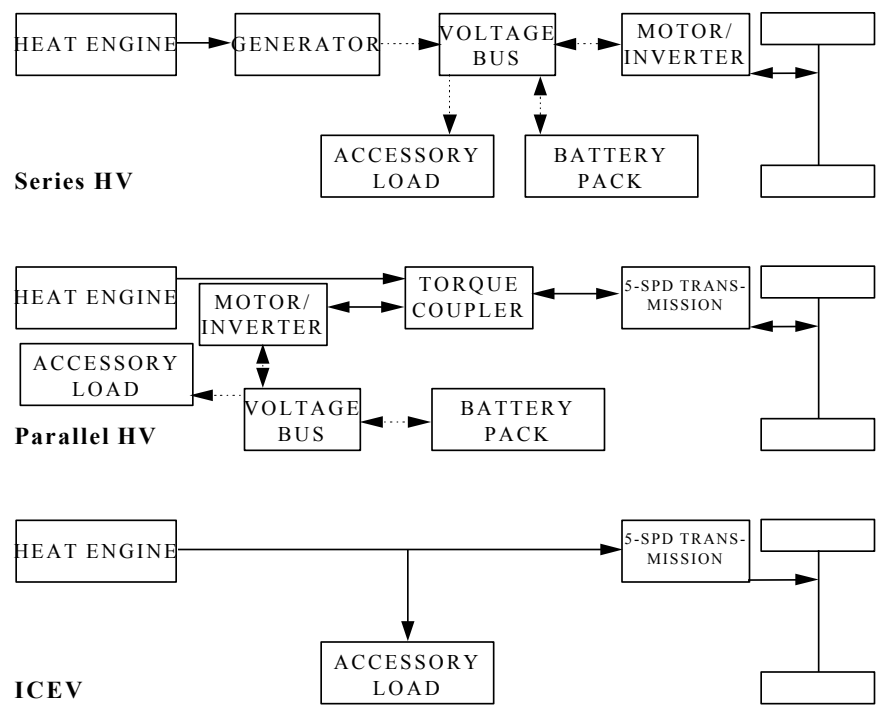

Figure 1. Energy-flow schematics of the series hybrid (top), parallel hybrid (middle), and ICEV (bottom). Solid lines indicate mechanical energy, and dashed lines indicate electrical energy.

\section{VEHICLE SPECIFICATION}

Component Specification - Table 1 lists the main component efficiencies and road load parameters assumed for this effort.

The heat engine used here is a direct-injection (DI) diesel, with a fuel-use map from the 5-cylinder, $85 \mathrm{~kW}$ Audi engine [10], scaled to peak efficiencies given in Table 1. See the "Scaling" section below for discussion of efficiencyversus-size-and-year considerations. The generator coupled to the diesel in the series hybrid vehicle (HV) is based on a permanent magnet motor/controller set from Unique Mobility. The traction motor/inverter set modeled here is based on the AC induction system being developed by Westinghouse. The batteries modeled here are advanced lead-acid, with characteristics adapted from Optima [11]. Vehicle drag parameters were chosen to define a Partnership for the New Generation of Vehicles (PNGV)-like vehicle with an aluminum-intensive body, heavy by Moore's standards but deemed achievable by those in industry interviewed by Duleep $[2,4]$. The "regenerative braking fraction" in the table is defined here as the fraction of braking energy during a given cycle that is provided to the electric drivesystem, with the balance, $60 \%$ in this case, handled by friction brakes.

Table 1. Vehicle summary data

\begin{tabular}{|c|c|c|c|}
\hline Parameter & Series HV & Parallel HV & ICEV \\
\hline \multicolumn{4}{|l|}{ Heat Engine } \\
\hline type & DI Diesel & DI Diesel & DI Diesel \\
\hline maximum power & $32 \mathrm{~kW}$ & $35 \mathrm{~kW}$ & $62 \mathrm{~kW}$ \\
\hline specific power & $\begin{array}{l}500 \mathrm{~W} / \mathrm{kg} \\
\quad[13]\end{array}$ & $\begin{array}{l}500 \mathrm{~W} / \mathrm{kg} \\
\quad[13]\end{array}$ & $\begin{array}{l}500 \mathrm{~W} / \mathrm{kg} \\
{[13]}\end{array}$ \\
\hline peak efficiency & $43 \%[10]$ & $43 \%[10]$ & $46.5 \%[13]$ \\
\hline avg. efficiency & $40.2 \%$ & $36.4 \%$ & $26.0 \%$ \\
\hline \multicolumn{4}{|l|}{ Generator } \\
\hline type & $\begin{array}{l}\text { Permanent } \\
\text { Magnet }\end{array}$ & -- & -- \\
\hline maximum power & $32 \mathrm{~kW}$ & -- & -- \\
\hline specific power & $\begin{array}{c}840 \mathrm{~W} / \mathrm{kg} \\
{[14]}\end{array}$ & -- & -- \\
\hline peak efficiency & $95 \%[14]$ & -- & -- \\
\hline avg. efficiency & $90 \%[14]$ & -- & -- \\
\hline \multicolumn{4}{|l|}{ Motor/Inverter } \\
\hline type & $\mathrm{AC}$ induction & $\mathrm{AC}$ induction & -- \\
\hline max. continuous power & $53 \mathrm{~kW}$ & $27 \mathrm{~kW}$ & -- \\
\hline specific power & $\begin{array}{l}820 \mathrm{~W} / \mathrm{kg} \\
{[15]}\end{array}$ & $\begin{array}{l}820 \mathrm{~W} / \mathrm{kg} \\
{[15]}\end{array}$ & -- \\
\hline peak efficiency & $92 \%[15]$ & $92 \%[15]$ & -- \\
\hline avg. efficiency & $86.8 \%$ & $89.4 \%$ & -- \\
\hline \multicolumn{4}{|l|}{ Battery Pack } \\
\hline type & $\begin{array}{l}\text { Advanced } \\
\text { Lead-Acid }\end{array}$ & $\begin{array}{l}\text { Advanced } \\
\text { Lead-Acid }\end{array}$ & -- \\
\hline maximum power & $63 \mathrm{~kW}$ & $32 \mathrm{~kW}$ & -- \\
\hline $\begin{array}{r}\text { specific power @ 50\% } \\
\text { SOC (including enclosure } \\
\text { and thermal management) }\end{array}$ & $800 \mathrm{~W} / \mathrm{kg}$ & $800 \mathrm{~W} / \mathrm{kg}$ & -- \\
\hline capacity & $2.4 \mathrm{kWh}$ & $1.2 \mathrm{kWh}$ & -- \\
\hline avg. round-trip efficiency & $87.6 \%$ & $87.7 \%$ & -- \\
\hline \multicolumn{4}{|l|}{ Transmission } \\
\hline type & 1 -spd & $\operatorname{man} .5$-spd & man. 5-spd \\
\hline avg. efficiency & $98 \%[16]$ & $92 \%[16]$ & $92 \%[16]$ \\
\hline \multicolumn{4}{|l|}{ Vehicle } \\
\hline $\mathbf{C}_{\mathrm{D}} \mathrm{A}$ & $0.4 \mathrm{~m}^{2}[12]$ & $0.4 \mathrm{~m}^{2}[12]$ & $0.4 \mathrm{~m}^{2}[12]$ \\
\hline $\mathbf{C}_{\text {rolling-resistance }}$ & 0.008 & 0.008 & 0.008 \\
\hline accessory load & 800 Welec & 800 Welec & 800 Wmech \\
\hline $\begin{array}{r}\text { regenerative braking } \\
\text { fraction }\end{array}$ & 0.4 & 0.4 & 0.4 \\
\hline 5-6 pass. glider mass & 840 kg [4] & $840 \mathrm{~kg}[4]$ & $840 \mathrm{~kg}[4]$ \\
\hline passenger/cargo mass & $136 \mathrm{~kg}$ & $136 \mathrm{~kg}$ & $136 \mathrm{~kg}$ \\
\hline $\begin{array}{r}\text { test mass (including driver/ } \\
\text { passenger/cargo) }\end{array}$ & $1243 \mathrm{~kg}$ & $1218 \mathrm{~kg}$ & $1214 \mathrm{~kg}$ \\
\hline
\end{tabular}

Table 1 also indicates propulsion component size and average energy efficiency over the combined federal 
cycle. Propulsion system components for each of the three vehicles were sized, using ADVISOR, in order to meet performance requirements set out by the US Consortium for Automotive Research (USCAR) for the PNGV effort [12]:

1. 0 to $96.5 \mathrm{~km} / \mathrm{h}(0$ to $60 \mathrm{MPH})$ in $12 \mathrm{~s}$

2. 64.4 to $96.5 \mathrm{~km} / \mathrm{h}$ (40 to $60 \mathrm{MPH}$ ) in $5.3 \mathrm{~s}$

3. 0 to $136.8 \mathrm{~km} / \mathrm{h}$ ( 0 to $85 \mathrm{MPH})$ in $23.4 \mathrm{~s}$, and

4. $6.5 \%$ gradeability at $88.5 \mathrm{~km} / \mathrm{h}(55 \mathrm{MPH})$.

The PNGV targets listed as 1-3 above must be attained at curb weight plus $136 \mathrm{~kg}$ for the driver and passenger, while the gradeability requirement is prescribed at gross vehicle weight with full accessory load for 20 minutes. We have differed from the PNGV specifications in that the gradeability requirement placed on the vehicles in this study is $6.5 \%$ at $88.5 \mathrm{~km} / \mathrm{h}$ indefinitely (until the fuel runs out), with average accessory load, at curb weight plus $136 \mathrm{~kg}$.

The HPU size for the hybrids is determined by the continuous gradeability requirement. Note that the HPU for the series HV is smaller than for the lighter parallel HV. This is because the $88.5 \mathrm{~km} / \mathrm{h}$ requirement, for a given gear ratio, requires the parallel HV's HPU to provide adequate climbing power at a certain speed which, in this case, is not the speed at which it develops maximum power. The series HV's HPU may operate at maximum power regardless of the vehicle speed; thus, its maximum power can be set to exactly the climbing power requirement. With the HPU sized for both vehicles, the motor and batteries are sized to meet the acceleration requirements, numbered one through three above.

Scaling - In this study, the efficiency map for an $85-\mathrm{kW}$ engine introduced in 1990 is used to describe the behavior of 32-, 35- and 62-kW engines [10]. For the 32- and $35-\mathrm{kW}$ engines, the original map shape and peak efficiency value were maintained, while the torque axis was compressed. We acknowledge the significant technical challenge involved in achieving such high peak efficiencies with a small engine, but are encouraged by continued progress by VW/Audi (which introduced a $66 \mathrm{~kW}$ DI diesel with $41.8 \%$ peak efficiency two years after the $85 \mathrm{~kW}$ benchmark) [17]. We believe $43 \%$ peak efficiency in $32-$ to $35-\mathrm{kW}$ diesel engines in 2005 is consistent with the Office of Advanced Automotive Technology's 2004 target of $45 \%$ peak efficiency for 40 - to $55-\mathrm{kW}$ engines, which is a goal at least some diesel manufacturers find reasonable $[13,18]$. We have assumed a peak efficiency of $46.5 \%$, the peak efficiency of current stateof-the-art heavy-duty diesel engines, for the $62-\mathrm{kW}$ engine in 2005, with its higher peak efficiency due to its larger size [13]. We expect the smaller (HV) engines to have lower specific power; the effect of changes in engine specific power can be derived using the data in Table 5 .

The tractive motors in this study, at outputs of 53 and $27 \mathrm{~kW}$, are significantly smaller than the $75-\mathrm{kW}$ motor from which their maps come. However, motors of these lower power levels with peak efficiencies of over $92 \%$ are available now [14]. We have not attempted to scale the efficiencies up, as would likely result from further development, for lack of data.

Series Hybrid Control Strategy - The strategy chosen here was a close-power-follower strategy where the hybrid power unit (HPU) power output closely follows the tractive motor output. Figure 2 shows the behavior of the vehicle propulsion system following this strategy over the first $315 \mathrm{~s}$ of the FUDS. The HPU power (represented by the dots) varies directly with the tractive motor power (represented by a solid line), but is higher by a state-of-charge-dependent factor to allow for losses in the generator and battery. In this strategy, the HPU power is given by (K1*(tractive_motor _power) + K2)*(SOChi-SOC)/(SOChi-SOClo), where SOChi and SOClo are threshold SOCs.

As the third chart in the figure indicates, this control strategy leads to nearly constant battery pack state-of-charge (SOC). (See the "Results and Discussion" section for a more detailed discussion of the control strategies considered here.)

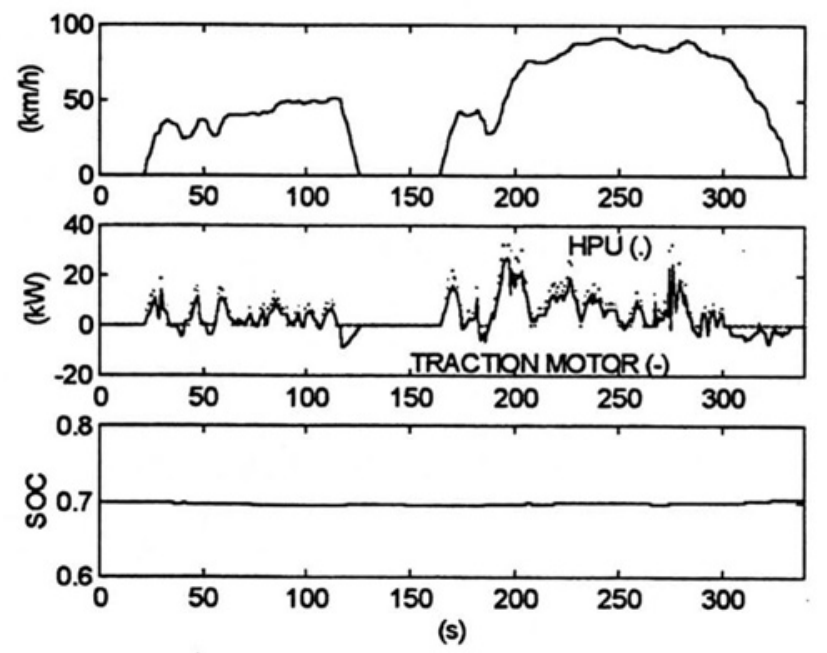

Figure 2. Close-Follower Control Strategy

We have chosen a power-follower strategy where the HPU power follows the motor power's second-by-second variation, which defines a vehicle that achieves $29.5 \mathrm{~km} / \mathrm{L}$ (69.4 MPG) on the combined federal drive schedule. This strategy was chosen because:

1) it leads to the best fuel economy in the control strategy design space of power-follower approaches considered here, and

2) it requires the HPU to immediately follow tractive power requirements, as occurs in the parallel hybrid and ICEVs. This leads the fuel economy estimate of each vehicle to be overestimated roughly equally due to the consistent neglect of transient effects, minimizing the effect of transient fuel use on the differences among the three vehicles' fuel economy.

This approach likely has no emissions benefit over ICEVs, and is chosen only for its fuel economy characteristics. Alternative control strategies with potentially better emissions characteristics are presented later in this paper. 
Parallel Hybrid Control Strategy - The parallel control strategy can be defined as follows:

- The HPU does not idle (it turns off when not needed).

- The motor performs regenerative braking regardless of the batteries' SOC.

- The HPU generally provides the power necessary to meet the trace, and

- the motor helps if necessary by providing additional torque, or accepting extra torque provided by the HPU for recharging the batteries.

The parallel hybrid control strategy was defined by two parameters: a vehicle speed below which the HPU is turned off, to allow for electric launch and no idling, and minimum HPU operating torque defined as a function of engine speed, which is the lowest torque output at which the HPU would operate whenever the tractive torque requirement is positive. When the minimum-allowed HPU operating torque exceeds that required to meet the trace, the balance of torque is used to drive the motor as a generator, recharging the batteries.

Figure 3 shows a sample portion of FUDS for this parallel vehicle. Note that the motor provides power when the vehicle needs additional torque to meet the driving, as described above. During the constant velocity portion of the driving cycle (from $\sim 90$ to $\sim 115 \mathrm{~s}$ ), the motor power is negative as the HPU provides recharging torque to the motor. As soon as the vehicle begins decelerating, the HPU shuts off, and the SOC increases while the motor captures regenerative braking energy. Note that during the final, slow deceleration, the motor power is negative but small in magnitude, leading to only a slight rise in SOC.
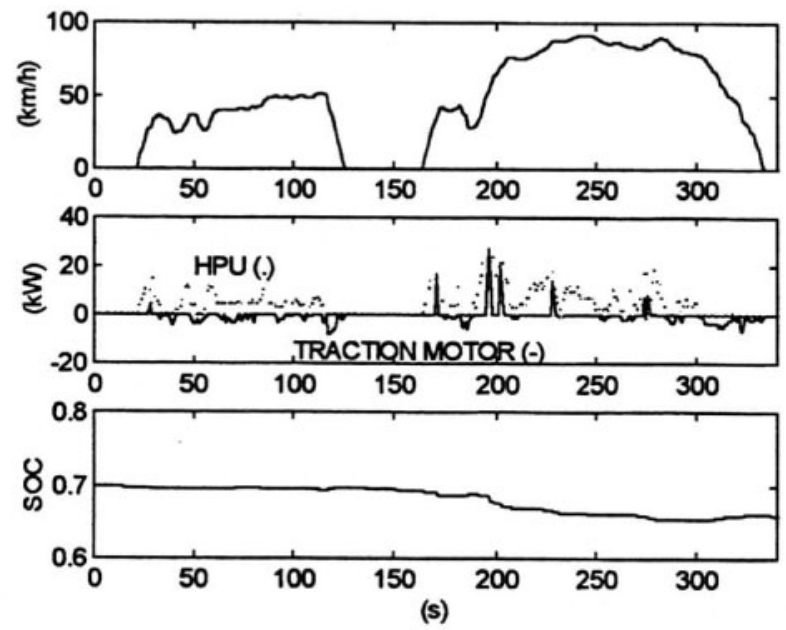

Figure 3. Parallel HV control strategy

\section{VEHICLE EVALUATION}

Vehicle Performance Simulator - ADVISOR is an empirical, physics- and map-based ADvanced Vehicle

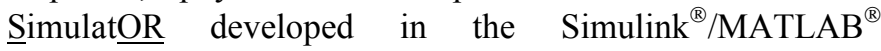
environment, the flexibility of which allows the development and evaluation of arbitrarily complex control strategies. ADVISOR uses fundamental equations of vehicle dynamics coupled with efficiency and/or power loss component maps to predict hybrid, internal-combustion-engine, and electric vehicle performance, range, and fuel economy. It has been compared to industry vehicle simulation programs and has been used by engineers in the hybrid program at the Chrysler Corporation. Reference eight provides more detail on this tool's application to vehicle system analysis.

Fuel Economy Calculations - The fuel economy results presented here must be understood as estimates: some uncertainty is introduced both by the model and the input data to the model. Additionally, the test procedure for determining hybrid vehicle fuel economy is a difficult problem on which debate on proper methodology continues. Due to the two energy-storage-modes of hybrid vehicles, the fuel economy calculation approach taken also may introduce uncertainty.

A Society of Automotive Engineers (SAE) task force has developed a draft hybrid vehicle test procedure which aims to properly account for changes in stored energy in charge-sustaining hybrids [19]. The unique feature of this approach is the running of two series of consecutive FUDS (for example) to determine fuel economy. The first series is started at the highest expected battery pack SOC and ends at some lower SOC, resulting in a fuel use and associated change in SOC. The second cycle is started at the lowest expected SOC and ends at some higher SOC, resulting in another fuel use and associated change in SOC. Linear interpolation is then used to predict the fuel economy estimate for the vehicle if the batteries had no net change in SOC. The benefit of using a test procedure such as this is that the uncertainty due to stored or discharged energy can be estimated by comparing the two fuel economies which bound the interpolated zero- $\Delta \mathrm{SOC}$ fuel economy.

Because the hybrids in this study tend to reach some nearly steady SOC after a number of cycles, a different approach was used to estimate their zero- $\Delta$ SOC fuel economy. The vehicles were run over four repeated cycles (one set of FUDS and one set of FHDS) with fuel economy and SOC measured only over the last cycle, and any fuel economy measurement associated with a $|\Delta \mathrm{SOC}|>1 \%$ (on the last cycle) was discarded. Because an exact match $(\triangle \mathrm{SOC}=0)$ is not required, some uncertainty is introduced by this method. However, we found it to be more repeatable than the SAE draft test procedure described above for the computational evaluation of these vehicles. It should be noted that our approach only works for hybrids whose SOC reaches some steady-state mean value over the cycle, is expected to be useful only for computational evaluation of hybrids, and is not as generally applicable as the draft SAE procedure. 


\section{RESULTS AND DISCUSSION}

FUEL ECONOMY ESTIMATES - The above defined vehicles were evaluated as described, and the resulting fuel economy estimates are in Table 2. From previous comparisons with automobile manufacturers' models, we estimate the model to be accurate to $\pm 10 \%$, while uncertainty in the component data projections is difficult to estimate. Thus these fuel economy estimates should be treated with care. On the other hand, inasmuch as the vehicle model over- or underestimates each vehicle's fuel economy equally, the model's uncertainty contribution is bias uncertainty and does not affect the accuracy of the computed fuel economy differences among the vehicles.

Table 2. Estimated gasoline-energy-equivalent fuel economy estimates on USEPA cycles

\begin{tabular}{|c|c|c|c|}
\hline Driving Cycle & Series HV & Parallel HV & ICEV \\
\hline FUDS & $26.6 \mathrm{~km} / \mathrm{L}$ & $27.4 \mathrm{~km} / \mathrm{L}$ & $21.1 \mathrm{~km} / \mathrm{L}$ \\
& $(62.6 \mathrm{MPG})$ & $(64.5 \mathrm{MPG})$ & $(49.6 \mathrm{MPG})$ \\
FHDS & $34.1 \mathrm{~km} / \mathrm{L}$ & $36.4 \mathrm{~km} / \mathrm{L}$ & $32.0 \mathrm{~km} / \mathrm{L}$ \\
& $(80.2 \mathrm{MPG})$ & $(85.6 \mathrm{MPG})$ & $(75.3 \mathrm{MPG})$ \\
combined & $29.5 \mathrm{~km} / \mathrm{L}$ & $30.8 \mathrm{~km} / \mathrm{L}$ & $24.9 \mathrm{~km} / \mathrm{L}$ \\
$(55 / 45)$ & $(69.5 \mathrm{MPG})$ & $(72.5 \mathrm{MPG})$ & $(58.6 \mathrm{MPG})$ \\
\hline
\end{tabular}

DRIVE-CYCLE EFFECTS - The parallel HV is $30 \%$ more fuel-efficient than the ICEV on the urban cycle (FUDS), 14\% more fuel-efficient on the highway cycle (FHDS), and 24\% more fuel-efficient on the combination. The series hybrid follows the same trend, being $26 \%$ more fuel-efficient than the ICEV on the FUDS, 7\% more fuelefficient on the FHDS, and 18\% more fuel-efficient on the combination. Note that both the parallel and series hybrids get similar fuel economy improvement on the FUDS, but that the parallel hybrid gets over twice the fuel economy improvement of the series on the FHDS. This is due in part to the parallel hybrid's HPU efficiently (especially on the FHDS) supplying power directly to the wheels, rather than having its output converted from mechanical to electrical and back to mechanical power, as occurs in the series hybrid.

The dependence of the fuel economy benefit of hybridization on drive-cycle is due to differences between the cycles in the number and nature of braking events, amount of idling time, and average power requirement. As braking frequency increases, so does the opportunity to recover braking energy. The more time an ICEV's engine idles in a given cycle, the more fuel may be saved by disallowing idling, as is done in both hybrid control strategies here. (Recall that the parallel vehicle powers its accessories electrically, and does not idle its heat engine). Also, the lower the average power requirement, in general, the lower the ICEV's average efficiency, and the greater the opportunity for hybridization to improve upon that efficiency [6].

The fuel economy improvement of the series and parallel hybrids over the ICEV is strongly dependent upon the driving cycle being considered. This is largely because the ICEV's fuel economy is much more sensitive to idling time and braking frequency than fuel economy of the hybrids considered here.

VEHICLE DRAG PARAMETER AND COMPONENT EFFICIENCY EFFECTS - The sensitivity of the fuel economy of each of the three baseline vehicles to various vehicle and component parameters were calculated using ADVISOR, and are presented in Table 3. The values presented indicated the percentage change in fuel economy due to a $1 \%$ increase in the given parameter (only). We took care to accurately estimate constant-performance sensitivity coefficients for each vehicle. Detailed discussion of the sensitivity coefficients is in the Appendix.

Table 3. Fuel economy sensitivity coefficients $(\%$ change in fuel economy on the combined federal cycle for a $1 \%$ increase in the given parameter)

\begin{tabular}{|c|c|c|c|}
\hline Parameter & Series HV & Parallel HV & ICEV \\
\hline average HPU eff. & 1.00 & 1.00 & 1.00 \\
$\begin{array}{c}\text { average motor eff. } \\
\text { average motor-as-a- } \\
\text { generator eff. } \\
\text { average battery } \\
\text { turnaround eff. }\end{array}$ & 0.91 & 0.05 & -- \\
mass & -- & 0.14 & -- \\
$\quad \mathbf{C}_{\mathbf{D}} \mathrm{A}$ & -0.60 & 0.13 & -- \\
$\begin{array}{c}\text { coeff. of rolling } \\
\text { resistance }\end{array}$ & -0.25 & -0.63 & -0.75 \\
$\begin{array}{c}\text { accessory load } \\
\text { regenerative braking } \\
\text { fraction }\end{array}$ & -0.26 & -0.25 & -0.22 \\
\hline
\end{tabular}

Three of the sensitivity coefficients in Table 3 require some explanation. The sensitivity coefficient for average motor efficiency indicates the percent change in fuel economy due to a $1 \%$ improvement in the tractive motor's efficiency while acting as a motor rather than as a generator. The sensitivity coefficient for the motor-as-a-generator refers to the dependence of fuel economy upon the tractive motor's efficiency when driven as a generator by the HPU (which occurs only in the parallel vehicle). The sensitivity coefficient labeled "regenerative braking fraction" refers to the dependence of fuel economy upon the tractive motor's efficiency when driven as a generator by the brakes.

We can use these sensitivities to estimate the effects of uncertain component efficiency assumptions. For example, the estimated $87.6 \%$ average turn-around efficiency for a high-power lead-acid battery in a hybrid vehicle may be optimistic, and we may choose a more conservative estimate of $80 \%$ average efficiency. The result of this revision is to change the fuel economy of the series vehicle by $[(0.80-$ $0.876) /(0.876)] \times 0.15=-0.013=-1.3 \%=-0.38 \mathrm{~km} / \mathrm{L}$ (-0.9 MPG), and the parallel hybrid's fuel economy changes by $[(0.80-0.876) /(0.876)] \times 0.13=-0.011=-1.1 \%=$ $-0.34 \mathrm{~km} / \mathrm{L}(-0.8 \mathrm{MPG})$. Of course, similar analyses can be performed with any of the parameters presented in Table 3, with good accuracy at changes of up to $\pm 10 \%$ and reasonable accuracy at changes of up to $\pm 20 \%$ in size. 
To summarize, with the exception of mass, road load parameters have a roughly equal effect on the fuel economy of all three vehicles, and therefore do not significantly affect the differences among them. Because this series hybrid uses a close-power-follower control strategy, its fuel economy is nearly as insensitive to battery efficiency as is the parallel hybrid's fuel economy. Hybrid fuel economy is less sensitive to regenerative braking effectiveness than to all other parameters considered here except the motor efficiency for the parallel vehicle.

Comparing fuel economy estimates to previous work - Using the sensitivities presented in Table 3, we can develop an estimate of the fuel economy benefit of hybridization assuming 100\% efficient components, for comparison with Tamor's estimates. We use

$$
F E=F E_{\text {table_2 }}+F E_{\text {table_2 }} \times \sum_{i} \xi_{i} \frac{\left(X_{i, \text { Tamor }}-X_{i, \text { table_1 }}\right)}{X_{i, \text { table_1 }}},
$$

where $F E$ is the new, estimated fuel economy, $F E_{\text {table } 2}$ is the fuel economy presented in Table $2, \xi_{i}$ are the sensitivity coefficients, and $X_{i}$ are the associated vehicle parameter values. Equation 1 implies that sensitivities may be used independently, which is true to a limited extent. Because the power flows in hybrid vehicles depend upon each other and the states of the vehicle components in complicated ways, hybrid vehicle fuel economy is a non-linear function of drivecycle and vehicle and component parameters. The effects of small vehicle-parameter changes may be combined reasonably with Equation 1, but using such an approach to combine large changes will lead to significant uncertainty in the result.

Equation 1, along with the combined federal fuel economies for the series HV and ICEV presented in Table 2, and the baseline vehicle mass, motor and battery efficiency, was used to predict the "Current" series-hybrid normalized fuel economy presented in Table 4.

Tamor used energy-throughput spectra (along with component data) to estimate the fuel economy of series and parallel hybrids relative to a lightweight Taurus using a "perfect" CVT. The hybrids' fuel economies were calculated for a range of vehicle masses and battery pack efficiencies. In this comparison, we consider one point in Tamor's range of estimates: the series HV with a $100 \%$-efficient energy storage system and the same mass as the baseline conventional-drivetrain vehicle in his study. We choose the $100 \%$-efficient energy storage for comparison to reduce the effect of uncertainty about Tamor's control strategy. (See the Appendix for a discussion of the battery-efficiencysensitivity/control-strategy relationship.)

To develop a fuel-economy-improvement-fromhybridization estimate for comparison to Tamor's estimate, we begin with the series HV defined in Table 1. We then apply Equation 1 to account for the differences between the point in Tamor's space chosen above and the Table 1 vehicle. Tamor's vehicle had all braking energy done by the electric drivetrain, while in our case, only $40 \%$ of braking energy was available for regeneration. Also, the point we chose from Tamor's calculations has a $100 \%$-efficient (round-trip) battery pack, while that of Table 1 is $87.6 \%$ efficient. Finally, our conventional-drivetrain vehicle has lower mass and a higher peak-efficiency-engine than does the series HV. The result of these modifications to the series HV computed here is shown in Table 4. We have used second-by-second simulation, component maps, and sensitivity coefficients to derive, within $5 \%$, the same fuel economy benefit of hybridization as did Tamor using different methods, for a somewhat heavier vehicle." This comparison is not a validation of either work, but indicates reasonable agreement using different approaches.

Table 4. Comparison of current normalized fuel economy on combined federal cycle estimate with Tamor's estimate for a series HV with equal mass and $100 \%$ efficient motor and battery pack [6]

\begin{tabular}{|c|c|c|}
\hline & Tamor & Current \\
\hline $\begin{array}{c}\text { Normalized Fuel Economy } \\
\text { (1=ICEV) }\end{array}$ & 1.47 & 1.54 \\
\hline
\end{tabular}

COMPONENT SPECIFIC POWER EFFECTS - It was noted above that neither hybrid vehicle's fuel economy (using the given control strategies) is particularly dependent upon battery efficiency. Let us examine the effect of battery specific power. The batteries in this comparison were assumed to have a power density of $800 \mathrm{~W} / \mathrm{kg}$, which results in a baseline battery mass of $78.4 \mathrm{~kg}$ for the series hybrid and $39.7 \mathrm{~kg}$ for the parallel hybrid. If we make the more conservative assumption of a $400 \mathrm{~W} / \mathrm{kg}$ battery pack, both pack masses double. We can estimate the fuel economy effect of this change using the mass sensitivity coefficients for the two vehicles and their baseline data from Table 1. The series vehicle's mass would change by $(78.4 / 1243)=6.3 \%$, and with a mass sensitivity coefficient of -0.60 , the series hybrid's fuel economy would change by $6.3 \% \times(-0.60)=-3.8 \%=$ $-1.12 \mathrm{~km} / \mathrm{L}(-2.6 \mathrm{MPG})$. The parallel vehicle's fuel economy change can likewise be estimated: $(39.7 / 1218) \times(-0.63)=$ $-2.1 \%=-0.65 \mathrm{~km} / \mathrm{L}(-1.5 \mathrm{MPG})$. Thus, the fuel economy of the series vehicle defined here is significantly more sensitive to battery specific power than the parallel hybrid because of the series hybrid's larger battery pack. Similar analyses can be performed with the specific power of other components as shown in Table 5.

Table 5. Fuel economy sensitivity coefficients (\% change in fuel economy on the combined federal cycle for a $1 \%$ increase in the given parameter) for component specific power

\begin{tabular}{|c|c|c|c|}
\hline Parameter & Series HV & Parallel HV & ICEV \\
\hline $\begin{array}{c}\text { HPU specific power } \\
\text { motor/inverter specific } \\
\text { power }\end{array}$ & 0.03 & 0.04 & 0.08 \\
battery pack specific power & 0.03 & 0.02 & -- \\
\hline
\end{tabular}

These results indicate that hybrid fuel economy, and thus the fuel economy benefit of drivetrain hybridization, does not depend strongly upon any one of the drivetrain components' specific power. It does indicate that the fuel

\footnotetext{
* Tamor's vehicles had a mass of $1020 \mathrm{~kg}$, while the ICEV mass here, to which we "corrected" the series hybrid mass using sensitivity coefficients, was $1214 \mathrm{~kg}$.
} 
economy of the series hybrid, with its more powerful motor and battery pack, is significantly more sensitive to changes in specific power of these components than is the fuel economy of the parallel hybrid.

\section{TRANSMISSION EFFECTS}

Number of gears - A 5-speed transmission was used here. It has been shown that increasing the number of gears in a transmission can improve fuel economy [4]. This is principally because the engine associated with a transmission with a greater number of gears may be able operate more of its time in good thermal efficiency regions, reducing the opportunity for hybridization, and reducing the fuel economy benefit of hybridization. The continuously-variable transmission (CVT) represents the limit of an infinite number of gears. As commercially available CVTs become more efficient, so that their losses do not negate the benefit of improved engine efficiency they offer, they may be used to make ICEV fuel economy more competitive with hybrid vehicle fuel economy.

Drivetrain configuration - A reasonable modification of the parallel hybrid analyzed here would be to move the motor closer to the wheels. That is, we might expect greater fuel economy by not having the motor transmit torque through the transmission, but rather directly to the vehicle's differential (through a single speed-reducing gear). This would reduce losses in the transmission by reducing the energy passed through it, while increasing losses in the motor by forcing its speed to be a fixed fraction of the tire speed. See Figure 4 for a diagram of this alternate configuration.

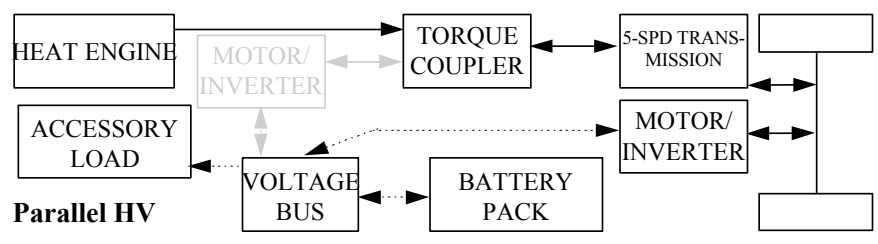

Figure 4. Parallel hybrid vehicle with motor connected directly to differential

We can estimate the fuel economy value of the motor-differential configuration over the one previously analyzed using the sensitivity coefficients presented above. Three energy-transfer modes will be affected: 1) motoring-mechanical energy provided by the motor will be subjected to fewer losses by circumventing the transmission, 2) regenerative braking--regenerative braking torque will likewise suffer fewer losses, and 3) HPU-to-motor charging-using the HPU to drive the motor as a generator will be significantly complicated by the interposition of the 5 -speed transmission, but that effect notwithstanding, the transmission will incur losses on the charging torque it transmits. We assume that the parallel motor's motoring and regenerative efficiencies are unchanged from the baseline, although its torque and speed output are tied to the wheel requirements by the motor-differential setup and not by the baseline motor-transmission-differential setup. We also assume that HPU-to-motor charging through the 5-speed transmission is feasible, despite the control challenges involved.

In the motoring regime, the motor-to-wheels efficiency is improved by the ratio (1-spd transmission efficiency $) /(5$-spd transmission efficiency $)=98 \% / 92 \%=1.065$, for a $6.5 \%$ improvement. Likewise, the regenerative braking, wheels-to-motor efficiency is improved by $6.5 \%$. The HPUto-motor efficiency is decreased by a factor of $92 \% / 98 \%=0.939$, for a $6.1 \%$ decrease. The combined effect of the motoring, regenerative braking, and charging efficiency changes can be computed using the sensitivities listed in Table 1 as "average motor eff.", "regenerative braking fraction", and "average motor-as-a-generator eff.", along with the changes computed above: $+6.5 \%,+6.5 \%$, and $-6.1 \%$. We have

$(6.5 \% \times 0.05)+(6.5 \% \times 0.07)+(-6.1 \% \times 0.14)=-0.9 \%$,

indicating a $0.9 \%$ drop from the baseline parallel vehicle fuel economy due to the change illustrated in Figure 4. This result is dependent the assumptions made about the transmission and motor efficiency and the drivetrain layout analyzed here, but indicates that the parallel hybrid fuel economy is not strongly dependent upon which of the two layouts analyzed is chosen.

EFFECT OF HPU TYPE ON FUEL ECONOMY DIFFERENCES - The size of the opportunity to avoid partload operation depends greatly on the type of HPU used in the vehicles compared. The diesels used in this effort have relatively large operating torque-speed regions of high efficiency compared to some spark-ignition engines. The fuel economy benefit due to the hybridization of certain sparkignition engine vehicles may therefore be greater than predicted here for the diesel engines. That is, the fuel economy difference between a spark-ignition hybrid and ICEV should be greater than the difference between a dieselpowered hybrid and ICEV, although both diesels should have better fuel economy than both spark-ignition engine vehicles. Although we have not quantified the difference between the fuel economy benefit of drivetrain hybridization of diesel- and spark-ignition-engine-powered ICEVs, we suggest that said quantification is perhaps not necessary. Given that one of the main aims of hybridization is high fuel economy, it seems reasonable to use a high-fuel-economy diesel as the ICEV benchmark.

Another opportunity hybrid vehicles offer is the use of alternative HPUs, such as gas turbines, fuel cells, and Stirlings in series (or perhaps parallel, in the case of the Stirling) HVs. Strictly speaking, we cannot isolate the benefit of drivetrain hybridization for vehicles using these powerplants because a conventional-drivetrain vehicle using them would undesirable, generally because of their poor dynamic response. However, we may wish to attribute the fuel economy benefits due to the use of alternative HPUs to the hybridization that makes them possible. These alternative HPUs offer the possibility of offering significantly more flexibility in fuel choice and improving vehicular emissions. 
EFFECT OF HYBRID CONTROL STRATEGY - In order to compare the hybrid vehicles fairly with the ICEV simulated in this effort, significant effort was expended in developing and selecting advantageous hybrid control strategies.

Parallel HV - The parallel hybrid control strategy was defined by two parameters: a vehicle speed below which the HPU is turned off, and minimum HPU operating torque defined as a function of engine speed, which is the lowest torque output at which the HPU would operate whenever the tractive torque requirement is positive. Where used in the control strategy, these parameters were multiplied by an SOC-dependent factor ((SOChi-SOC)/(SOChi-SOClo)) designed to keep the SOC within a desired range. Changes in these parameters did not strongly affect the fuel economy of the vehicle, but rather only the steady average SOC that was attained. As stated before, significant work in control strategy development and evaluation is necessary to make hybrids reach their full fuel economy potential. This initial effort in parallel hybrid control strategy evaluation could be more fully developed, and future work is planned. In this work, the parallel hybrid fuel economy was nearly independent of the control strategy parameters used.

Series HV - A 'thermostat' hybrid control strategy (in which the HPU operates at a constant power level starting when the battery pack SOC reaches some bottom setpoint and stopping when the SOC has climbed to some upper setpoint) was evaluated along with a spectrum of power-follower control strategies. A power-follower control strategy, as discussed by Anderson and Pettit, is one in which the HPU power is dictated by the tractive motor power, but perhaps limited in its rate-of-change [20].

The spectrum of power-follower strategies that were investigated is defined by two independent variables: 'minimum HPU power' and 'averaging time'. Minimum HPU power is the power command below which the HPU is turned off. Averaging time is the size of the time window over which tractive motor power is averaged to derive the HPU power command. The HPU power command is the sum of an SOC-dependent factor and a scalar multiple of the averaged motor power. Figure 5 shows the dependence of this power-follower series hybrid fuel economy on the combined federal cycle upon these control strategy parameters.

Note that as the averaging time falls, fuel economy increases. Physically, as the averaging time falls, the HPU power level changes more quickly, following the power requirements of the tractive motor more closely. Thus, a smaller averaging time means more of the electric power generated by the HPU is used by the motor without passing through the batteries, and battery losses are decreased.

Two effects of 'minimum HPU power' are competing, particularly at low averaging times, leading to a best-fuel-economy point vertically in the center of the plot. As the minimum/cutoff power decreases, the HPU is allowed to operate at low powers which correspond to low efficiencies. As the minimum power increases, the HPU more frequently alternately charges the batteries (operating at or above its cutoff power) and shuts off, allowing the batteries to discharge. The shape of this map, then, is largely determined by battery turnaround efficiency and to a perhaps lesser extent by the HPU efficiency map.

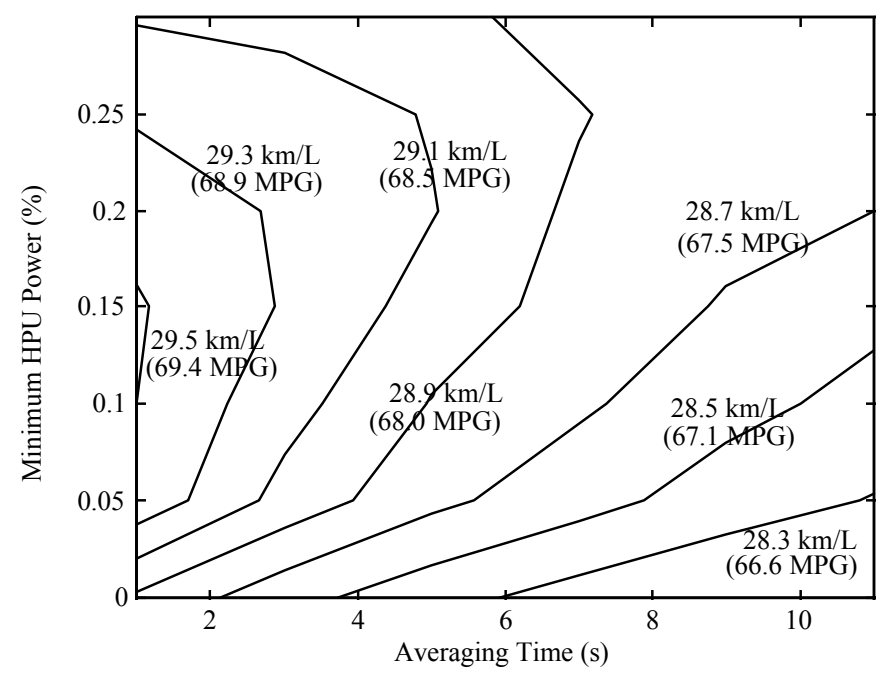

Figure 5. Fuel economy vs. control strategy parameters for series hybrid

The thermostat control strategy, using the peak HPU efficiency point and high and low SOC points of $80 \%$ and $40 \%$, leads to a fuel economy of $31.1 \mathrm{~km} / \mathrm{L}$ (73.2 MPG). Over the range in Figure 5, the power-follower strategy leads to a maximum fuel economy of $29.5 \mathrm{~km} / \mathrm{L}$ (69.4 MPG) and a minimum of less than $28.3 \mathrm{~km} / \mathrm{L}$ (66.6 MPG). Series hybrid fuel economy variations of at least $9 \%$, then, can be traced to reasonable but suboptimal control strategies. Control strategy selection is an extremely important step in the design of hybrid vehicles for good fuel economy and emissions which we have not fully addressed. The sensitivity of fuel economy to control strategy shown here is likely a conservative estimate due to the simplifying assumptions (for example, neglect of the fuel economy effect of thermal and throttle transients).

\section{CONCLUSIONS}

With the understanding that hybrid vehicle design decisions are made for many reasons other than to maximize fuel economy, we have analyzed the dependence of hybrid fuel economy upon various vehicle and component design parameters. The main conclusions of this paper are as follows:

1. The parallel hybrid defined here achieves fuel economy that is $24 \%$ better than the ICEV while the series betters the ICEV by $18 \%$.

2. The parallel hybrid is $4 \%$ more fuel-efficient than the series hybrid.

3. Lightweight midsized hybrid vehicles with low aerodynamic drag and rolling resistance using near- to mid- 
term technology can achieve $30 \mathrm{~km} / \mathrm{L}$ (70.6 MPG) (gasolineequivalent).

4. The series hybrid control strategy strongly influences its fuel economy, and a 'thermostat' control strategy, neglecting thermal transient effects, is among the best of those examined here, considering fuel economy only.

5. When a series hybrid uses an HPU capable of following motor power demands on a second-by-second basis, a control strategy can be used that reduces the sensitivity of fuel economy to battery efficiency to the same level as in a parallel hybrid.

6. The parallel and series hybrid fuel economies are not strongly dependent upon component specific power, but series hybrids are more sensitive to battery and motor specific power than are parallel hybrids.

7. The series hybrid's fuel economy is less sensitive to regenerative braking effectiveness than to any other vehiclelevel parameter, and the parallel hybrid's fuel economy is less sensitive only to motor efficiency than to regenerative braking effectiveness. Doubling regenerative braking capture effectiveness improves series hybrid fuel economy by $10 \%$ and parallel hybrid fuel economy by $7 \%$.

8. This parallel hybrid's fuel economy is not significantly changed by connecting the motor directly to the differential rather than to the 5-speed transmission.

9. Control strategy development for a charge-sustaining parallel HV is challenging and warrants further investigation.

\section{ACKNOWLEDGMENT}

This work was sponsored by the Department of Energy (DOE) as part of the MRI-managed DOE Hybrid Vehicle Propulsion System Program. We would also like to gratefully acknowledge the inputs of Terry Penney, Robert Rehn, Robert Farrington, Michael Tamor, and the anonymous SAE reviewers.

\section{REFERENCES}

1. Hybrid Electric Vehicle Total Energy Cycle Analysis: Work Plan (Draft), Center for Transportation Research, Argonne National Laboratory, January 26, 1996

2. Moore, T. C., A. B. Lovins, "Vehicle Design Strategies to Meet and Exceed PNGV Goals," SAE Paper No. 951906

3. Moore, T. C., "Tools and Strategies for Hybrid-Electric Drivesystem Optimization," SAE Paper No. 961660

4. Duleep, K.G., "Automotive Technologies to Improve Fuel Economy to 2015, Draft Report," Prepared by Energy and Environmental Analysis for the Office of Technology Assessment, December 1994

5. Duleep, K. G., "Fuel Economy Potential of Light Duty Vehicles in 2015+, Draft Final Report," Prepared by Energy and Environmental Analysis for Martin Marietta Energy Systems, April 1995
6. Tamor, M. A., "Hybrid Vehicle Modeling," presented at ENV '96, February 1996

7. Mason, W. T., U. Kristiansson, "Hybrid EVs versus Pure EVs: Which Gives Greater Benefits?" SAE Paper No. 94C017

8. Wipke, K., M. Cuddy, "Using an Advanced Vehicle Simulator (ADVISOR) to Guide Hybrid Vehicle Propulsion System Development," Presented at the NESEA 1996 Sustainable Transportation Conference, New York, NY, September 16, 1996

9. Sovran, G., M. S. Bohn, "Formulae for the TractiveEnergy Requirements of Vehicles Driving the EPA Schedules," SAE Paper No. 81084

10. Stock, D., R. Bauder, "The New Audi 5-Cylinder Turbo Diesel Engine: The First Passenger Car Diesel Engine with Second Generation Direct Injection," SAE Paper No. 900648, 1990

11. Deep Cycle Battery Specification and Technical Information, Optima Batteries, Inc., September 6, 1996

12. Swiatek, R., of Chrysler Corp., Personal Communication, October 3, 1995

13. Draft National Plan for Advanced Automotive Technologies, Office of Advanced Automotive Technologies, August 16, 1996

14. Product Information on the CaliberEV 32 Permanent Magnet Traction Drive System, Unique Mobility, June 3, 1996

15. Lesster, L.E., et al., "An Induction Motor Power Train for EVs--The Right Power at the Right Price," Advanced Components for Electric and Hybrid Electric Vehicles: Workshop Proceedings, October 27-28, 1993, Gaithersburg, Maryland

16. "Efficiency guidelines for future manual transmissions," Automotive Engineering, January 1996, pp. 45-49

17. Neumann, K. H., M. Kuhlmeyer, J. Pohle, "The new 1,9 L TDI diesel engine with low fuel consumption and low emission from Volkswagen and Audi," Société des Ingenieurs de l'Automobile Paper No. 92038

18. Reynolds, S., of Detroit Diesel Corp., Personal Communication, December 5, 1996

19. Draft SAE J1711 Recommended Practice, "Measuring the Electric Energy Consumption, All Electric Range, Fuel Economy, and Exhaust Emissions of Hybrid Electric Vehicles," February 24, 1995

20. Anderson, C., E. Pettit, "The Effects of APU Characteristics on the Design of Hybrid Control Strategies for Hybrid Electric Vehicles," SAE Paper No. 950493 


\section{APPENDIX}

Fuel economy sensitivity coefficients for the vehicles were computed using the following equation:

$\xi_{i}=\frac{F E_{110 \%}-F E_{90 \%}}{F E_{\text {baseline }(100 \%)}} \times \frac{1}{1.10-0.90}$,

where $i$ indicates the parameter being considered, $F E_{\text {baseline }(100 \%)}$ is the fuel economy for the parameter at its baseline value, and $F E_{110 \%}$ and $F E_{90 \%}$ refer to fuel economies corresponding to parameter values of $110 \%$ and $90 \%$ of the baseline value.

Sensitivities to road load parameters other than mass $\left(\mathrm{C}_{\mathrm{D}} \mathrm{A}\right.$, coefficient of rolling resistance, and regenerative braking fraction) were computed using constant-efficiency vehicle representations. This approach was used to minimize the effect of the road load parameters on driveline component efficiencies. For example, if the coefficient of rolling resistance increases, the force required to propel the vehicle at any time over the cycle (regardless of speed) increases, leading to higher torque requirements of the transmission and motor and/or heat engine. Generally, increasing the torque output of a component increases its efficiency. Thus, the effect of increasing the coefficient of rolling resistance in a vehicle whose drivetrain component efficiencies depend upon torque (and speed) would be to increase those average component efficiencies. This must be avoided to isolate the effect of the coefficient-of-rolling-resistance increase.

To compute the fuel economy sensitivity to mass, drivetrain components for the $10 \%$ more massive and $10 \%$ less massive vehicles were sized to provide 0 to $96.5 \mathrm{~km} / \mathrm{h}$ times equivalent to that of the baseline vehicle.

Fuel economy sensitivities to drivetrain component (HPU, motor, and battery) efficiency were computed using vehicle representations that included power loss maps. This approach, in contrast to the constant efficiency approach, was used to preserve the baseline vehicle's time history of power flows among the components. These flows depend upon the battery SOC at a given time as well as motor power demands, both of which are dependent upon the drivetrain component efficiency history.

Note that the sensitivity coefficient for the HPU for all three vehicles is unity, implying that for a $1 \%$ increase in engine efficiency (for example, from $40 \%$ to $40.4 \%$ ), there will be a $1 \%$ increase in fuel economy. Another way of stating this is that fuel economy is directly proportional to HPU efficiency. This is as one would expect: all energy used on-board the vehicle (assuming it is charge-sustaining, and the fuel economy test is corrected to zero change-in-SOC) comes from fuel conversion occurring in the HPU.

The sensitivity coefficient for the motor for the series hybrid $(0.91)$ is over 18 times that of the parallel hybrid $(0.05)$. This difference is due to the much smaller amount of motor energy used by the parallel hybrid than by the series. In the parallel vehicle, most tractive energy is supplied directly by the HPU, while in the series, all tractive energy must pass through the motor. Note that the motor and HPU sensitivity coefficients differ for the series hybrid because while all energy used by the vehicle passes through the HPU, the same is not true of the motor: accessory draw is independent of the motor.

Table A1 (reprise of Table 3). Fuel economy sensitivity coefficients (\% change in fuel economy on the combined federal cycle for a $1 \%$ increase in the given parameter)

\begin{tabular}{|c|c|c|c|}
\hline Parameter & Series HV & Parallel HV & ICEV \\
\hline $\begin{array}{c}\text { average HPU eff. } \\
\text { average motor eff. }\end{array}$ & 1.00 & 1.00 & 1.00 \\
$\begin{array}{c}\text { average motor-as-a- } \\
\text { generator eff. }\end{array}$ & -.91 & 0.05 & -- \\
$\begin{array}{c}\text { average battery } \\
\text { turnaround eff. }\end{array}$ & 0.15 & 0.14 & -- \\
$\begin{array}{c}\text { mass } \\
\text { C }\end{array}$ & -0.60 & 0.13 & -- \\
coeff. of rolling \\
$\begin{array}{c}\text { resistance } \\
\text { accessory load }\end{array}$
\end{tabular}

The vehicle fuel economy sensitivities to the remaining parameters in Table A1 are nearly independent of vehicle type. For the battery efficiency, the closeness of the series and parallel hybrid sensitivities is somewhat coincidental, as this sensitivity is highly dependent upon control strategy. However, the control strategies used in the two vehicles are (intentionally) similar in that they minimize battery energy throughput. Changes in battery efficiency become more important as more energy is passed through the battery. The sensitivity of a thermostat-control-strategy series hybrid's fuel economy to battery efficiency would be much higher than shown here, since the effect of the thermostat control strategy is to alternately fill and empty the batteries.

The small differences among the sensitivities to road

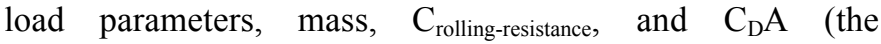
aerodynamic drag product) are to be expected. The relative values of these sensitivities depend only upon the relative values of the road load parameters themselves. Road load parameters are identical for all vehicles, with the exception of mass, which differs by less than $2.4 \%$ among the three. Accessory load sensitivities are likewise dependent upon road load parameters, and are nearly identical for the three vehicles. Vehicle-to-vehicle differences in any one of these parameters can be ascribed to uncertainty in the calculation.

Sovran and Bohn use the standard vehicle tractive force equation, $F=(1 / 2) \rho C_{D} A v^{2}+m g\left(\right.$ Crolling-resistance $\left.+C_{r r l} v\right)+m a$, along with driving cycle data to analytically determine sensitivity coefficients or "influence coefficients," as they are called in the paper [9]. We can use the equations presented there to develop sensitivity coefficients against which to compare the coefficients we developed here, for each vehicle. 
The sensitivity coefficients developed using Sovran's methods are presented in Table A2.

Comparing Tables $\mathrm{A} 1$ and $\mathrm{A} 2$, we can see that all the predicted sensitivities to aerodynamic drag product $\left(\mathrm{C}_{\mathrm{D}} \mathrm{A}\right)$ and coefficient of rolling resistance agree to within $9.1 \%$. The mass sensitivity coefficients for the ICEV agree to within $2.7 \%$. Using Sovran and Bohn approach for the sensitivity of fuel economy to mass is inappropriate, however, as evidenced by the difference between the two sets of estimates ( -0.60 vs. -0.76 for the series and -0.63 vs. -0.76 for the parallel). Sovran and Bohn's equations were developed for a ICEV, without regenerative braking. The hybrids in this study employ regenerative braking; therefore they recover some of the energy expended to accelerate the vehicle, reducing the effect mass has on the total tractive energy required, and thus, fuel required for a given cycle.

Table A2. Fuel economy sensitivity coefficients developed using the methods of Sovran and Bohn (\% change in fuel economy over the combined federal cycle for a $1 \%$ increase in the given parameter). Note that Sovran and Bohn's "influence coefficients" were positive; their signs were changed for consistency with previous sensitivity coefficients presented.

\begin{tabular}{|c|c|c|c|}
\hline Parameter & Series HV & Parallel HV & ICEV \\
\hline mass & -0.76 & -0.76 & -0.77 \\
$\mathbf{C}_{\mathbf{D}} \mathbf{A}$ & -0.24 & -0.24 & -0.23 \\
$\begin{array}{c}\text { coeff. of rolling } \\
\text { resistance }\end{array}$ & -0.26 & -0.24 & -0.24 \\
\hline
\end{tabular}

